\title{
DIET OF BARN OWL TYTO ALBA STERTENS HARTERT, 1929 IN A PORTION OF CAUVERY DELTA, TAMIL NADU, INDIA
}

\section{P. Neelanarayanan}

Post Graduate and Research Department of Zoology, Nehru Memorial College (Autonomous), Puthanampatti, Tiruchirappalli District, Tamil Nadu 621007, India

Email:pnn31@hotmail.com, pnn31@yahoo.co.in

\begin{abstract}
The diet of Barn Owls was studied between February 1993 and January 1995. The analysis of 4,030 regurgitated pellets yielded 6,157 prey items, of which the mean percentage of prey composition of Barn Owl comprising rodents were to the tune of 32.79 for Bandicota bengalensis, 29.40 for Millardia meltada, 3.90 for Mus booduga, 2.15 for Tatera indica, 6.38 for Rattus rattus and 6.99 for unidentified species. The Barn Owls consumed $352.18 \mathrm{~g}$ of prey comprising six species of small mammals during this period. Among these, B. bengalensis was $45.13 \%$ followed by M. meltada (32.84\%), R. rattus (10.98\%), Suncus murinus (6.43\%), T. indica $(3.73 \%)$ and $M$. booduga $(0.89 \%)$. The observed mean prey items/pellet was 1.51 in the first year and 1.46 in the second year of study suggesting the fact that Barn Owls consume more than one prey/day. The results of the present study indicate that the Barn Owls are potential hunters of rodent pests and are good controlling agents in crop fields and fallow lands.
\end{abstract}

\section{KEYWORDS}

Bandicota bengalensis, diet, Millardia meltada, prey biomass, pellet analysis, small mammals, Tyto alba

The food habit of the Barn Owl has been studied in detail and more extensively than that of any other bird of prey, because of its wide distribution and the ease with which regurgitated pellets containing non-digestible remains of prey items can be found for analysis (Taylor, 1994). The literature review on major diet of barn owls from six continents was reported to be rodents, the most important small mammalian group. Out of 52 key studies, on the Barn Owl's diet by Taylor (1994), rodents constituted more than $50 \%$ of all prey items in 47 studies and they formed more than $75 \%$ of all prey items in 33 studies, suggesting that Barn Owls are excellent rodent hunters in nature.

The remarkable diversity of rodent fauna of the Indian subcontinent is shown by 46 genera, 135 species and about 300 subspecies (Ellerman, 1961), of them 14 species have been found to be of economic importance (Prakash, 1988). Rodents are very well known to be the major pests of agricultural crops and stored food grains (Prakash \& Mathur, 1987). In addition, they are also reservoirs of a large numbers of pathogens many of which, if transmitted to human and domestic animals, may cause outbreaks of diseases often with high morbidity and mortality (Gratz, 1994).

In the Cauvery delta, 'the granary of southern India', four species of field rodents are found. They are (i) The Lesser Bandicoot Rat (Bandicota bengalensis), (ii) The Soft-furred Field Rat (Millardia meltada), (iii) The Indian Field Mouse (Mus booduga) known to inhabit the crop fields (Sivaprakasam, 1988 \& Neelanarayanan et al., 1996), and (iv) The Indian Gerbil
(Tatera indica) found in barren lands around the crop fields (Sivaprakasam, 1988; Neelanarayanan et al., 1996).

Prakash (1992) also stated that no concrete effort has so far been undertaken towards biological control of rodents in India, and he has further emphasized the need for undertaking such studies to estimate correctly their role in effective control of various field rodent pests. In order to fill up this lacuna, the present study, i.e., the predatory role of Barn Owl over rodent pests was designed with the objective to study the prey composition of Barn Owl in wild through regurgitated pellet analysis,

\section{Material and Methods}

The present study was carried out in an area of $35 \mathrm{~km}^{2}$ in Tranquebar taluk, Nagappattinam district, Tamil Nadu state $\left(10^{\circ} 40^{\prime}-11^{\circ} \mathrm{O} 6^{\prime} \mathrm{N} \& 79^{\circ} 22^{\prime}-79^{\circ} 49^{\prime} \mathrm{E}, 13.11 \mathrm{~m}\right)$ for 24 months from February 1993 through January 1995. The population estimation of Barn Owls was carried out in the daytime as suggested by Anon (1993), i.e., when they are in their roosting/ nesting sites. The Barn Owls' roosting/nesting sites were identified by using indirect signs, such as regurgitated pellets, milky white droppings and prey remains as suggested by Nagarajan et al. (1993), Taylor (1994) and Santhanakrishnan (1995). Besides, the information given by the local residents were also useful in locating the roosting/nesting sites of Barn Owls.

Population estimation was made in nine temple towers (Fig. 1): Thirukkalacheri - Sri Naganatha Swamy Temple (TSNST), Poraiyar - Sri Ayyanar Temple (PSAT), Poraiyar - Sri Perumal Temple (PSPT), Poraiyar - Sri Kumaran Temple (PSKT), Poraiyar - Sri Viswanatha Swamy Temple (PSVST), Erukkattancheri - Sri Kalakaleshwarar Temple (ESKT), Thillaiyadi - Sri Sarntharaikatha Swamy Temple (TSSaST), Thillaiyadi - Sri Perumal Temple (TSPT) and Thiruvidaikazhi - Sri Subramanya Swamy Temple (TSSST). The observed number of adult Barn Owls, sub-adults, nestlings and eggs were recorded from the above roosting/nesting sites once a month during the two-year study period.

The diet of Barn Owls over different prey spectrum was studied by an indirect method, namely, the regurgitated pellet analysis, which is a reliable technique than other techniques as far as owls are concerned (Errington, 1932; Glading, et al., 1943) and particularly for Barn Owls (Marti, 1987). The pH of the Barn Owl's stomach is higher (less acidic) than that of many other predatory birds and hence most of the bones of ingested prey are left undigested (Smith \& Richmond, 1972). 
Further, the skulls and mandibles of even the most delicate small mammal and bird prey are found intact in the pellets and can easily be identified (Taylor, 1994).

The regurgitated pellets of Barn Owls were collected from the nine roosting/nesting sites. They were bagged separately and labelled and brought to the laboratory for analysis. Before analysis, the pellets were kept in an oven at $70^{\circ} \mathrm{C}$ for $24 \mathrm{hr}$ to kill the associated invertebrate parasites (Santhanakrishnan, 1995). The pellets were then analysed, individually by using $8 \% \mathrm{NaOH}$ as suggested by Neelanarayanan et al. (1998), a modified method of Scheuler (1972) and Marti (1987) who suggested $3 \%$ and $10 \% \mathrm{NaOH}$ (mass analysis), respectively.

The identification of small mammalian representatives in the diet of Barn Owl up to species level was made by using the keys developed by Neelanarayanan et al. (1998). In the absence of mandibles, other bones like skulls, limb bones, pectoral and pelvic girdles and synsacra (in the case of birds) were useful, especially for identifying and quantifying the mammalian (rodents), avian and amphibian prey. A hand lens or low power binocular microscope was employed to identify insect exoskeleton (Marti, 1987; Neelanarayanan et al., 1995). In a pellet, one set of mandibles (left and right) was counted as one prey species.

In order to know the contribution of each prey species in the Barn Owl's diet, they were converted into proportions and presented in tables. The mean prey items per pellet were calculated as follows:

Mean prey items/pellet $=\frac{\text { Total no. of prey items observed in a month }}{\text { Total no. of pellets collected in a month }}$

\section{Results And Discussion}

Population of Barn Owl

The total number of adult Barn Owls, subadults and chicks were found to be 249, 64, and 99 during February 1993 to January 1994 while they were 168, 9 and 38 during February 1994 to January 1995, respectively. It should also be noted that the population of Barn Owls (adults + subadults + chicks) were high (approximately 50\%) during the first year of study (February '93-January '94) than during second year of study (February '94-January '95). The total number of eggs observed during first and second year of study was 152 and 111 , respectively (Tables 1 ).

\section{Barn Owl prey items and frequency}

The diet composition of Barn Owls in terms of frequency observed during February 1993 to January 1995 is presented in Table 1. Analysis of 4030 regurgitated pellets revealed that small mammals, viz., B. bengalensis, M. meltada, M. booduga, T. indica and Rattus rattus; an insectivorous mammal, Suncus murinus; amphibians, birds and insects were the constituents of the diet of Barn Owls. Of these, B. bengalensis (1953nos.) and M. meltada (1908 nos.) were found to be consumed by the Barn Owls in great numbers during both years of study. $S$. murinus (567), unidentified rodent species (461), R. rattus (393), M. booduga (254), T. indica (129), insects (21) and birds (1) formed the diet in addition, for both years of study (Table 1).
Analysis of 4030 regurgitated pellets yielded 6157 prey items. The magnitude of predatory pressure of Barn Owl was found to be high (3636 prey items) during the first year of study and low (2521 prey items) during the next year. The total prey consumption of rodents of agricultural importance constituted, $3199+1899$ (total 5098 prey items) during the study period (Table 1).

\section{Prey items - proportion}

The prey spectrum observed in the diet of Barn Owls, in terms of proportion is summarized in Table 2. The mean percentage of prey composition of Barn Owl's diet were to the tune of 32.79 for B. bengalensis, 29.40 for M. meltada, 3.90 for $M$. booduga, 2.15 for $T$. indica, 6.38 for $R$. rattus and 6.99 for unidentified rodent species. Among the total prey items, the rodents of agricultural importance accounted for $81.61 \%$ of total prey consumption during both years of study. It should also be noted here that during the first year of study, $M$. meltada were consumed by the Barn Owls in great numbers than $B$. bengalensis, though, during the second year, M. meltada was replaced by $B$. bengalensis (Table 2 ).

Earlier, consumption of small mammals by Barn Owls have been reported by Evans \& Emlen (1947), Marti (1974), Colvin (1984), Knight \& Jackman (1984), Lenton (1984), Pikula et al. (1984), Colvin \& McLean (1986), Rosenberg (1986), Campbell et al. (1987), Smal (1987), Marti (1988), Manning \& Knox Jones (1990), Neelanarayanan et al. (1995), Taylor (1994), Santhanakrishnan (1995). The observed dominance of $B$. bengalensis and M. meltada in food composition of Barn Owl could be attributed to their high incidence in different crop fields. Sivaprakasam (1988) and Kanakasabai et al. (1995) have also found that $B$. bengalensis was a dominant vertebrate pest of different crops cultivated in Cauvery delta, Tamil Nadu, followed by $M$. meltada and M. booduga. These three rodent pests formed $66.09 \%$ of total food composition of Barn Owl as reported in the present study. In addition to small mammals, the Barn Owl's diet comprised representatives of amphibians, birds and insects and this observation is in concurrence with those of Santhanakrishnan $(1987,1995)$ Taylor (1994) and Neelanarayanan et al. (1995).

The results of the present study imply that Barn Owls have their own prey option, but still are opportunistic predators, which is in accordance with those of Mikkola (1983), Hegdal \& Blaskiewicz (1984) and Manning \& Knox Jones (1990)

\section{Prey items - biomass}

Earlier, Kanakasabai et al. (1998) reported that the wet mean prey body weight of the six species of small mammals as $81.39 \pm 56.55$ (Range $=10-250 \& n=142$ ) for B. bengalensis, $60.61 \pm 35.84$ (Range $=10-95 \& n=153$ ) for M. meltada, 12.33 2.13 (Range=8-16 \& n=26) for M. booduga, $101.81 \pm 44.79$ (Range=20-210 \& $n=47$ ) for $T$. indica, $98.48 \pm 40.92$ (Range $=25-190 \& n=51$ ) for $R$. rattus and $39.89 \pm 10.77$ (Range=20-55\& $n=23$ ) for S. murinus. For obtaining the mean prey weight of each species, the prey frequency of each species was multiplied by the aforesaid calculated mean prey weight of that species (Kanakasabai et al., 1998). 
Table 1. Prey composition (in frequency from nine nesting / roosting sites) of Barn Owls revealed from pellet analysis.

\begin{tabular}{|c|c|c|c|c|c|}
\hline & Prey Items & $\begin{array}{l}\text { February } 1993 \\
\text { To January } 1994\end{array}$ & $\begin{array}{l}\text { February } 1994 \\
\text { to January } 1995\end{array}$ & $\begin{array}{l}\text { Total (February } 1993 \\
\text { to January 1995) }\end{array}$ & Rank \\
\hline \multicolumn{2}{|c|}{ Total number of pellets analysed } & 2288 & 1742 & 4030 & \\
\hline $\begin{array}{l}\text { Total number of } \\
\text { Barn Owls observed }\end{array}$ & $\begin{array}{l}\text { Adults } \\
\text { Sub adults } \\
\text { Chicks } \\
\text { Eggs }\end{array}$ & $\begin{array}{l}249 \\
64 \\
99 \\
152\end{array}$ & $\begin{array}{l}168 \\
09 \\
38 \\
111\end{array}$ & $\begin{array}{l}417 \\
73 \\
137 \\
263\end{array}$ & \\
\hline Rodents & $\begin{array}{l}\text { B. bengalensis } \\
\text { M. meltada } \\
\text { M.booduga } \\
\text { T. indica } \\
\text { R. rattus } \\
\text { Unidentified Rodent Species } \\
\text { Total ( Rodents) }\end{array}$ & $\begin{array}{l}977 \\
1386 \\
188 \\
66 \\
227 \\
355 \\
3199\end{array}$ & $\begin{array}{l}976 \\
522 \\
66 \\
63 \\
166 \\
106 \\
1899\end{array}$ & $\begin{array}{l}1953 \\
1908 \\
254 \\
129 \\
393 \\
461 \\
5098\end{array}$ & $\begin{array}{l}1 \\
2 \\
7 \\
8 \\
6 \\
5\end{array}$ \\
\hline Insectivore & S. murinus & 269 & 298 & 567 & 3 \\
\hline \multirow[t]{2}{*}{$\begin{array}{l}\text { Amphibians } \\
\text { Birds } \\
\text { Insects }\end{array}$} & & $\begin{array}{l}168 \\
0 \\
0\end{array}$ & $\begin{array}{l}302 \\
1 \\
21\end{array}$ & $\begin{array}{l}470 \\
1 \\
21\end{array}$ & $\begin{array}{c}4 \\
10 \\
9\end{array}$ \\
\hline & Grand Total & 3636 & 2521 & 6157 & \\
\hline
\end{tabular}

Table 2. Mean percentage (based on prey frequency from nine nesting / roosting sites) of different prey items in the diet of Barn Owls

\begin{tabular}{|c|c|c|c|c|c|}
\hline & Prey Items & $\begin{array}{l}\text { February } 1993 \\
\text { To January } 1994\end{array}$ & $\begin{array}{l}\text { February } 1994 \\
\text { to January } 1995\end{array}$ & $\begin{array}{l}\text { Total (February } 1993 \\
\text { to January 1995) }\end{array}$ & Rank \\
\hline \multicolumn{2}{|c|}{ Total number of pellets analysed } & 2288 & 1742 & 4030 & \\
\hline & & \multicolumn{4}{|c|}{ Values are in Mean Percentage } \\
\hline \multirow[t]{7}{*}{ Rodents } & B. bengalensis & 26.85 & 38.73 & 32.79 & 1 \\
\hline & M. meltada & 38.11 & 20.70 & 29.40 & 2 \\
\hline & M.booduga & 5.17 & 2.63 & 3.90 & 7 \\
\hline & T. indica & 1.81 & 2.48 & 2.15 & 8 \\
\hline & R. rattus & 6.24 & 6.53 & 6.38 & 6 \\
\hline & Unidentified Rodent species & 9.77 & 4.22 & 6.99 & 5 \\
\hline & Total (Rodents) & 87.96 & 75.30 & 81.61 & \\
\hline Insectivore & S. murinus & 7.39 & 11.81 & 9.60 & 3 \\
\hline \multirow{4}{*}{$\begin{array}{l}\text { Amphibians } \\
\text { Birds } \\
\text { Insects }\end{array}$} & & 4.62 & 11.99 & 8.30 & 4 \\
\hline & & 0.00 & 0.04 & 0.02 & 10 \\
\hline & & 0.00 & 0.82 & 0.41 & 9 \\
\hline & Grand Total & 99.97 & 99.95 & 99.94 & \\
\hline
\end{tabular}

The total biomass of all small mammalian prey of Barn Owl during 24 months study period is given in Table 3. The Barn Owls consumed 3,52,184.13g of prey comprising six species of small mammals during this period; $1,58,954.67 \mathrm{~g}$ of B. bengalensis, 1,15,643.88g of M. meltada, 3,131.82g of M. booduga, 13,133.49g of T. indica, 38,702.64g of $R$. rattus and $22,617.63 \mathrm{~g}$ of $S$. murinus. Of these, the observed proportion of consumption of B. bengalensis and M. meltada was $45.13 \%$ and $32.84 \%$ respectively, which is more than three-fourth $(77.97 \%)$ of total prey intake by the Barn Owls. It is thus confirmed that in terms of both frequency and biomass, the Barn Owls consumed rodent pests of economic importance in Cauvery delta, namely, B. bengalensis and M. meltada in larger quantities than other prey items.

Regarding total prey $(\mathrm{g})$ consumption, five rodents of economic importance alone accounted for $93.57 \%$ in 24 months. Earlier, Perrins (1982), and Smith and Cole (1989) reported that five species of rodents formed $80 \%$ of diet (in terms of biomass) of Barn Owl.
According to Marti (1987), both prey frequency and biomass quantification methods are equally valuable because the former provides better information on the relative impact a raptor upon various prey species, while the latter may give a more accurate evaluation of the relative importance of different prey species in the diet. Only the small mammal representatives were considered for prey biomass quantification in the present study.

\section{Mean prey items/pellet}

The observed mean prey items/pellet (from February 1993 through January 1995) is presented in Table 4. In the present investigation, a maximum of 2.02 prey items/pellet was observed during April 1993 while a minimum of 1.06 prey items/pellet was observed during April 1994. The average observed mean prey items/pellet was 1.51 in the first year and 1.46 in the second year of study (Table 4). These results apparently reveal the fact that the Barn Owls consume more than one prey per day since they regurgitate every day and after every meal. The observations of the present investigation 
Table 3. Total biomass (g) (estimated by using mean body weight of respective species) and the proportions of the small mammalian prey consumed by the Barn Owls between February 1993 and January 1995

\begin{tabular}{llll}
\hline Prey species & Total Biomass $(\mathbf{g})$ & $\%$ & Rank \\
\hline B. bengalensis & $1,58,954.67$ & 45.13 & 1 \\
M. meltada & $1,15,643.88$ & 32.84 & 2 \\
M. booduga & $3,131.82$ & 0.89 & 6 \\
T. indica & $13,133.49$ & 3.73 & 5 \\
R. rattus & $38,702.64$ & 10.98 & 3 \\
Total (Rodents) & $3,29,566.50$ & 93.57 & \\
S. murinus (Insectivore) & $22,617.63$ & 6.43 & 4 \\
Grand Total & $3,52,184.13$ & 100.00 & \\
\hline
\end{tabular}

Table 4. Mean prey / pellet items observed during the pellet analysis

\begin{tabular}{lll}
\hline Year/Month & $\mathbf{1 9 9 3 - 1 9 9 4}$ & $\mathbf{1 9 9 4 - 1 9 9 5}$ \\
\hline February & 1.22 & 1.46 \\
March & 1.68 & 1.46 \\
April & 2.02 & 1.06 \\
May & 1.63 & 1.46 \\
June & 1.41 & 1.63 \\
July & 1.45 & 1.63 \\
August & 1.43 & 1.75 \\
September & 1.40 & 1.35 \\
October & 1.69 & 1.48 \\
November & 1.25 & 1.26 \\
December & 1.12 & 1.38 \\
January & 1.76 & 1.62 \\
Mean & $\mathbf{1 . 5 1}$ & $\mathbf{1 . 4 6}$
\end{tabular}

are in accordance with the observations of Hamilton \& Neil (1981) and Neelanarayanan et al. (1995).

In conclusion, the results of the present study indicate that the Barn Owls are potential hunters of rodent pests and can therefore be used for controlling rodent pests in crop fields and fallow lands. Steps should be initiated not only to protect and conserve Barn Owls but also to increase their population in situ by way of installing nest boxes. They should also be bred in captivity for release near crop fields after thorough investigation and in compliance with scientific reintroduction protocol base don the guidelines of the Reintroduction Specialist Group. Solid efforts are needed to include Barn Owl as one of the major components in Integrated Rodent Pest Management (IRPM), at the earliest possible opportunity.

\section{REFERENCES}

Anon. (1993). A Local Barn owl survey. An information leaflet (No. 8) of the Barn Owl trust, Waterleat, Ashburton, Devon, TQ13, 7HU U.K.

Campbell, R.W., D.A. Manuwal \& A.S. Harestad (1987). Food habits of the common Barn Owls in British columbia. Canadian Journal of Zoology 65: 578-586.

Colvin, B.A. (1984). Barn Owl foraging behaviour and secondary poisoning hazard from rodenticide use on farms. Ph.D. Thesis. Bowling Green State University, Bowling Green, Ohio.

Colvin, B.A. \& E.B. McLean (1986). Food habits and prey specificity of the common Barn Owl in Ohio. Ohio Journal of Science 86: 76-80.

Ellerman, J.R. (1961). The Fauna of India, Mammalia, Rodentia, Vol. III (Plates I \& II). Government of India, New Delhi, 849pP.

Errington, P.L. (1932). Technique of raptor food habit study. Condor 34: 7586.
Evans, F.C. \& J.T. Jr. Emlen (1947). Ecological notes on the prey selected by a Barn Owl. Condor 49(1): 3-9.

Glading, B., D.F. Tillotson \& D.M. Selleck (1943). Raptor pellets as indicators of food habits. California Fish and Game 29: 92-121.

Gratz, N.G. (1994). Rodents as carriers of disease, pp.85-108. In: Buckle, A.P. and R.H. Smith, R.H. (eds), Rodent Pests and Their Control. CAB International, Wallingford, U.K.

Hamilton, K.L. \& R.L. Neil (1981). Food habits and Bioenergetics of a pair of Barn Owls and owlets. American Midl. Nat. 106(1): 1-9.

Hegdal, P.L. \& R.W. Blaskiewicz (1984). Evaluation of the potential hazard to Barn Owls of TALON (broadifacoum bait) used to control rats and house mice. Environm. Toxicol. Chem. 3: 167-179.

Kanakasabai, R., P. Neelanarayanan \& R. Nagarajan (1995). Artificial perches use by common Barn Owl (Tyto alba stertens) in paddy fields. Proceedings of the National symposium on Recent Trends in Indian Wildlife Research, A.V.C. College, Mayiladuthurai, South India, pp.5660.

Kanakasabai, R., P. Neelanarayanan \& R. Nagarajan (1998). Quantifying Barn Owl (Tyto alba stertens) prey frequency and biomass. Proceedings of the First National Symposium on Birds in Agricultural Ecosystem, A.N.G.R. Agricultural University, Hyderabad, pp.153-157.

Knight, R.L. \& R.E. Jackman (1984). Food niche relationships between Great Horned Owls and Common Barn Owls in Eastern Washington. Auk 101: 175-179.

Lenton, G.M. (1984). The feeding and breeding ecology of Barn Owls Tyto alba in Peninsular Malaysia. Ibis 126: 551-575.

Manning, R.W. \& J.K. Jones (1990). Remains of Small Mammals recovered from Barn Owl pellets from Crosby county, Texas. The Texas Journal of Science 42: 311-312.

Marti, C.D. (1974). Feeding ecology of four sympatric Owls. Condor 76: 45-61.

Marti, C.D. (1987). Raptor food habit studies, pp.67-79. In: Pendleton, B.G., B.A. Millsap, K.W. Kline and D.A. Bird (eds), Raptor Management Techniques Manual. National Wildlife Federation of Science and Technology Service No.10, Washington D.C.

Marti, C.D. (1988). A long term study of food niche dynamics in the Common Barn Owl: Comparision within and between populations. Canadian Journal of Zoology 66: 1803-1812.

Mikkola, H. (1983). Owls of Europe. T. and A.D. Poyser, Carlton, U.K. Nagarajan, R., P. Neelanarayanan \& R. Kanakasabai (1993). Tips for the identification of Common Barn Owl nests. Newsletter for Birdwatchers 33(5): 93.

Neelanarayanan, P., R. Nagarajan \& R. Kanakasabai (1995). The Common Barn Owl, Tyto alba: A potential predator of rodent pests. Pestology 19(9): 34-37.

Neelanarayanan, P., R. Nagarajan \& R. Kanakasabai (1996). Burrow morphology of field rodents. Journal of the Bombay Natural History Society 93(2): 238-241.

Neelanarayanan, P., R. Nagarajan \& R. Kanakasabai (1998). Studying diet of Barn Owl (Tyto alba stertens) by pellet analysis. Proceedings of the First National Symposium on Birds in Agricultural Ecosystem, A.N.G.R. Agricultural University, Hyderabad, pp.125-131.

Perrins, M.R. (1982). Prey specificity of the Barn Owl, Tyto alba, in the Great Fish River Valley of the Eastern Cape Province. South African Journal of Wildlife Research 12: 14-25.

Pikula, J., M. Beklova \& V. Kubik (1984). The breeding bionomy of Tyto alba. Acta Scientiarum Naturalium. Academic Scientiarum Bohemoslovacae Brno 18: 1-53.

Prakash, I. (1988). Rodent problems in India. FAO Plant Protection Bulletin 36(3): 145-148.

Prakash, I. (1992). Future Lines of Research, pp.685-692. In: Prakash, I. and P.K. Ghosh (eds.). Rodents in Indian Agriculture. Vol. 1. Scientific Publishers, Jodhpur.

Prakash, I. \& R.P. Mathur (1987). Management of Rodent Pests. Indian Council of Agricultural Research, New Delhi, 133pp.

Rosenberg, C.P. (1986). Barn Owl habitat and prey use in Agricultural Eastern Virginia. M.Sc., Thesis, College of Wilham and Mary, Williamsburg, VA. 
Santhanakrishnan, R. (1987). Studies on population, food habits and nesting of Barn Owl, Tyto alba (Scopoli) in a portion of Cauvery basin. M.Phil., dissertation, A.V.C. College, Mayiladuthurai, 42pp. (unpublished). Santhanakrishnan, R. (1995). Ecology of Barn Owl, Tyto alba (Scopoli) with special reference to its population, feeding and breeding in Mayiladuthurai, Tamil Nadu, south India. Ph.D. dissertation, Bharathidasan University, Tiruchirappalli, South India.

Schueler, F.W. (1972). A new method of preparing Owl pellets: boiling in $\mathrm{NaOH}$. Bird Banding 43: 142.

Sivaprakasam, C. (1988). Studies on the burrow ecology, population and food habits of field rodents in and around Mannampandal and Arupathy areas. M.Sc., Thesis, Bharathidasan University, Tiruchirappalli (unpublished).

Smal, C.M. (1987). The diet of the Barn Owl Tyto alba in southern Ireland with reference to a recently introduced prey species - the Bank Vole, Clethrionomys glarealus. Bird Study 34: 113-125.

Smith, C.R. \& M.E. Richmond (1972). Factors affecting pellet egestion and gastric pH in the Barn Owl. Wilson Bulletin 84: 179-186.

Smith, J.D.B. \& J. Cole (1989). Diet of the Barn Owl Tyto alba, in the
Tanami Desert, northern Territory. Australian Wildlife Research 16: 611624.

Taylor, I.R. (1994). Barn Owls: Predator Prey Relationships and Conservation. Cambridge University Press, Cambridge, U.K., 303pp.

\section{AcKnowledgements}

The financial assistance rendered by ICAR, New Delhi for carrying out this research work is gratefully acknowledged. I am highly indebted to Dr. R. Kanakasabai for his valuable guidance during the study; to the principal and the management of A.V.C. College for their help and encouragement; to Messrs. R. Balu, B.Sc., and Elangovan A.V.C. College for help and assistance during many field trips; to the temple authorities for permitting me to study the Barn Owl populations' nesting/roosting in temple towers. The moral support and encouragement extended by secretary, principal and H.O.D. of Zoology, Nehru Memorial College (Autonomous), Puthanampatti are gratefully acknowledged.

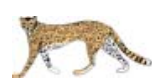

CASE REPORT

ZOOS' PRINT JOURNAL 22(8): 2781-2785

\section{ENZYMATIC AND HORMONAL STUDIES IN ACACIA EBURNEA INFECTED WITH RAVENELIA ESCULENTA}

\section{K.R. Gandhe ${ }^{1}$ and Aniket Kuvalekar ${ }^{2}$}

${ }^{1}$ Reader, PG Research Centre, Department of Botany, Modern College of Arts, Science and Commerce, Shivajinagar, Pune, Maharashtra 411005, India; ${ }^{2}$ UGC - SRF, PG Research Centre, Department of Botany, Modern College of Arts, Science and Commerce, Shivajinagar, Pune, Maharashtra 411005, India

Email: ${ }^{1}$ kanchan.gandhe@gmail.com (corresponding author)

plus web supplement of 1 page

\section{Abstract}

Ravenelia esculenta Naras. and Thirum. infects Acacia eburnea Willd. producing hypertrophy in infected parts, mainly thorns, inflorescence, flowers and fruits. The hypertrophied parts are edible and consumed with relish. The severe stages of the disease are marked by pronounced hypertrophy in the infected parts, frequently 10 times or more. The disease progress is marked by gradual increase in hypertrophy and severe stages show presence of brown aecial cups. The process of disease development was studied to analyse various biochemical changes. Enzymatic studies showed significant shifts in the activities of enzymes like Polyphenol oxidase (PPO) (EC 1.14.18.1), Peroxidase (POX) (EC 1.11.1.7) and IAA Oxidase (IAAO). Activity of PPO was found to be in accordance with the quantity of total phenols. POX activity was found to be maximum during severe infection stage. Maximum IAAO activity was noticed during initiation of hypertrophy. These studies help to reveal the enzymatic changes during disease development by fungi. Changes in IAAO activities are suggestive of possible involvement of IAA, its derivatives and GA interaction in development of hypertrophied structures.

\section{KEYwords}

Acacia eburnea, disease development, GA, IAA Oxidase, Peroxidase, Polyphenol Oxidase, Ravenelia esculenta.

Ravenelia esculenta Naras. and Thirum. is a rust fungus that infects Acacia eburnea Willd. (Narasimhan \& Thirumalachar, 1961). The infected organs show hypertrophy at various stages of disease development (Narasimhan \& Thirumalachar, 1961). The hypertrophy is marked by presence of brown coloured aecial cups visible on the infected organ (Image $1^{w}$ ). The hypertrophied structures are edible and are consumed along with liquor. This hypertrophy is an outcome of altered host physiology and hormonal metabolism. There are reports of various host-fungus interactions that lead to alterations in the overall physiology of host. Gandhe et al. (2004) have screened the infected host to analyse the host-fungus interaction in Ravenelia esculenta. From these studies it was found that besides other metabolic alterations, the infected parts accumulate enormous amounts of aluminium and hence consumption of these infected structures pose potential threat of neural diseases like Alzheimer's disease. Shaw \& Samborski (1957) have discussed the physiological changes in mildew and rust infected wheat leaves, initial increase in respiration rate being one of the early physiological responses to pathogen attack. It has been observed that fungal, bacterial and viral diseases also lead to alterations in the biochemical constituents of hosts. These may range from change in chlorophyll contents (Prasanna et al., 2004) due to infection of Citrus Yellow Mosaic virus in leaves of Citrus sinensis, accumulation of soluble and reducing sugars due to infection of Alternaria brassicae to Brassica

${ }^{\mathrm{w}}$ See Image $1^{\mathrm{w}}$ in the web supplement at www.zoosprint.org

Manuscript 1723; (C) ZOO; Date of publication 21 July 2007; Received 20 February 2007; Finally accepted 15 June 2007 